\title{
A construção de um programa de letramento informacional e arte educação
}

The development of an information literacy and art education program

Alexandra César Zinn, Kelley Cristine Gonçalves Dias Gasque.

Universidade de Brasília.

RESUMO: Analisa a interligação dos conteúdos de letramento informacional aos conteúdos de Arte no ensino médio por meio de pesquisa descritiva realizada com arte-educadores da secretaria de educação do Distrito Federal, regional de ensino do Recanto das Emas. Os docentes pesquisados participaram de curso básico de formação em letramento informacional com intuito de subsidiar a etapa posterior que consistiu em responderem rodadas de questionários intercaladas por feedbacks. O estudo utilizou o método Delphi, os instrumentos de pesquisa foram questionários estruturados com perguntas fechadas e abertas. Os resultados revelaram a viabilidade de aplicação da proposta, apesar dos desafios a serem superados, relacionados principalmente à incipiência da formação em letramento informacional dos docentes em geral, à deficitária infraestrutura das escolas e à organização curricular vigente.

PALAVRAS-CHAVE: Letramento Informacional. Multiletramento. Arte Educação.
ABSTRACT: This article analyzes the interconnection of Information Literacy content to Art content in High School by a descriptive research with art educators who work at the Public Education Schools (Recanto das Emas regional area) in the Distrito Federal Government. The educators who were researched, they had participated in the information literacy basic course, which has the purpose to support the next step of the research, which they answered some group of questionnaires, that after each of them, the art educators received a feedback of it. This study used the Delphi method and the research tools were questionnaires structured with some objective and subjective questions. The results disclosed the feasibility to apply this kind of literacy purposed in the study, even though the challenges related to the general incipient information literacy of the educators, the infrastructure problems and the actual organization of the curriculum school.

KEYWORDS: Information Literacy; Multiliteracy; Art Education.

\author{
Correspondência \\ Alexandra César Zinn \\ Universidade de Brasília. \\ Brasília, DF. \\ Email: alexandrazinn@hotmail.com
}

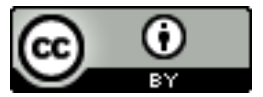

JITA: CD. User training, promotion, activities, education. 


\section{INTRODUÇÃ̃}

Na sociedade contemporânea, o sucesso pessoal e profissional dos indivíduos, bem como o desenvolvimento social e a redução das desigualdades estão diretamente ligados à equidade de oportunidades de acesso à educação (DEMO,1994; FERREIRA,2000; RODRIGUES,2009). Ao considerar a discrepância na qualidade do ensino ofertado pelas escolas públicas e particulares, reconhece-se o letramento informacional fator preponderante na formação dos estudantes. Portanto, é possível buscar, propor e praticar atividades pedagógicas no âmbito escolar que contribuam para o pleno crescimento da capacidade informacional dos estudantes com intuito de desenvolver o pensamento crítico e reflexivo, competências indispensáveis para a ação autônoma e responsável dos cidadãos.

Neste contexto, as atividades pedagógicas nas instituições de ensino precisam, de acordo com Gasque (2010), voltar-se para o desenvolvimento do letramento informacional dos estudantes, valorizando a capacidade de buscar e selecionar de maneira ética e eficaz, as informações disponíveis, bem como compreendê-las, apreendê-las e contextualizá-las para construção de conhecimentos gerais e das diversas disciplinas curriculares, inclusive Arte.

O presente artigo, resultado de pesquisa de mestrado, apresenta a análise da possibilidade de interligação dos conteúdos de letramento informacional aos conteúdos de Arte do ensino médio. Para tanto, os especialistas pesquisados participaram de curso de formação básico em letramento informacional, a fim de fornecer subsídios para responderam as posteriores rodadas de questionários. Cada rodada foi seguida de feedback aos participantes e os dados tabulados e analisados após a conclusão desse processo.

O método Delphi, método de prospecção de cenários, apresentou-se como ferramenta adequada diante do objetivo geral a ser alcançado. Foi aplicado com professores de Arte atuantes no ensino médio da secretaria de educação do Distrito Federal, regional de ensino do Recanto das Emas, cidade localizada aproximadamente a 26 km de distância de Brasília.

Para tanto, apresenta-se breve revisão de literatura dos conceitos de multiletramento, letramento informacional e arte educação, os quais constituem os principais aspectos tratados nesse estudo.

\section{MULTILETRAMENTO, LETRAMENTO INFORMACIONAL E ARTE EDUCAÇÃO}

Nas práticas pedagógicas contemporâneas o conceito de multiletramento está em voga nos currículos e demais documentos relacionados. É também amplamente discutido quanto à relevância para a democratização de culturas, linguagens, conteúdos e metodologias no ensino (ROJO, 2009).

O conceito surgiu em 1996, quando o grupo de educadores, denominado New London

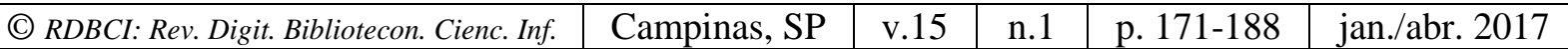


Group, publicou o manifesto A Pedagogy of Multiliteracies: Designnig Social Futures, em que destaca a necessidade das instituições escolares considerarem nas práticas de ensino a diversidade de letramentos emergentes na sociedade. Assim, o termo multiletramento surge para abranger a multimodalidade e a multiculturalidade dos letramentos (BEVILAQUA, 2013).

Rojo e Moura (2012) afirmam que o conceito de multiletramento aponta para dois tipos de multiplicidades presentes na sociedade atual, a multiplicidade cultural das populações e a multiplicidade semiótica dos textos produzidos e comunicados. O letramento informacional insere-se nessa perspectiva de maneira ampla, pois especificamente, de acordo com Gasque (2012), consiste em um processo de aprendizagem voltado não somente ao aspecto textual, mas para o desenvolvimento da busca e do uso da informação.

Harris (2008) afirma que as competências de criação, localização, avaliação e uso da informação nos mais diferentes e variados suportes e formatos ocorrem nos contextos da comunidade, em que os significados e valores estão imersos. Isso significa compreender melhor o contexto de implementação dos programas.

O letramento informacional pode contribuir para o desenvolvimento do pensamento crítico e reflexivo dos indivíduos. Letrados na busca, uso e comunicação da informação, esses cidadãos têm condições de colaborar na superação dos graves problemas, das mais diversas ordens que assolam a humanidade contemporânea (GASQUE, 2012).

Para que isso ocorra, é necessário que os aprendizes desenvolvam as competências informacionais a partir da educação infantil. Nesse contexto, deve-se iniciar a inserção do letramento informacional nas escolas, por meio de programas que visem a integração com o planejamento educacional, o currículo e o plano das disciplinas (MATA, 2014).

Programas de letramento informacional nos últimos anos foram elaborados, implementados, avaliados e adaptados em diversos países. Em geral, com abordagem voltada ao trabalho colaborativo entre o grupo de professores e bibliotecários das instituições. Kovalik, Yutzey, Piazza (2012) destacam que o trabalho nesta concepção proporciona o aumento do nível de confiança dos professores em relação ao próprio letramento, e, por conseguinte maior benefício para os estudantes envolvidos.

Tendo em vista a necessidade de um currículo voltado para implementação de programas de letramento informacional na educação básica brasileira, Gasque (2012) elaborou proposta de organização dos conteúdos por série/ano, que integra os conteúdos do letramento aos conteúdos propostos pelos Parâmetros Curriculares Nacionais (PCN'S). Ressalta, contudo, que a proposta não deve ser transposta a toda e qualquer realidade, sendo necessária a adaptação ao contexto escolar em que o programa será realizado.

$\mathrm{O}$ entendimento do letramento informacional como processo de aprendizagem contínuo, que deve ser desenvolvido em parceria com as diversas disciplinas e não em

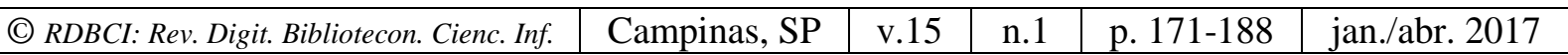


projetos isolados da biblioteca (GASQUE, 2012), instiga iniciativas de interdisciplinaridade como o proposto por este estudo.

O ensino de Arte nas instituições escolares consolidou-se historicamente por meio do movimento político dos profissionais da área e, atualmente, consiste em componente curricular obrigatório na educação básica. Na educação infantil e nos anos iniciais do ensino fundamental, devido à regulamentação recente da lei, que instituiu a referida obrigatoriedade (BRASIL, 2016), os pressupostos curriculares ainda serão sistematizados conforme ocorrido nas demais etapas da educação básica (anos finais do ensino fundamental e ensino médio).

No ensino médio, Arte está atrelada à área de linguagens (CMEBEM, 2013), fato que atesta a relevância da Proposta Triangular de Ana Mae Barbosa, paradigma contemporâneo vigente na arte educação. A proposta sofreu influência da abordagem pedagógica Freireana, que preconiza o letramento como ferramenta libertadora. Assim, Barbosa (1998) reconhece a necessidade de valorização do letramento para a leitura visual.

Outros vértices, além da leitura de obras de arte, são considerados na Proposta Triangular: a produção e a contextualização. A produção refere-se ao fazer artístico por meio da aplicação do conhecimento adquirido pelo estudo teórico dos preceitos da área, e a contextualização refere-se à possibilidade de integração dos conhecimentos históricos da arte, aos contextos histórico, social, psicológico, antropológico, geográfico, dentre outros (BARBOSA, 1998).

\section{METODOLOGIA}

A presente pesquisa tem natureza descritiva. De acordo com Bhattacherjee (2012), essa proposta examina e documenta detalhadamente o fenômeno de interesse. A população pesquisada compõe-se de docentes de Arte do ensino médio da rede pública de ensino do Distrito Federal, Regional de Ensino do Recanto das Emas. O universo da população descrita abrange 12 docentes, e a amostra não possui mínimo ou limite de participantes dentro do universo apresentado, por se tratar de pesquisa qualitativa.

A pesquisa adota abordagem qualitativa, perspectiva fundamental diante da complexidade do fenômeno educacional, que envolve aspectos como formação continuada docente, prática de ensino, grade horária, estrutura curricular, dentre outros. Explorar um fenômeno social significa considerar as variáveis envolvidas, conhecer e reconhecer as interferências e relações, em que as etapas do processo possuem relação interdependente entre si (FLICK, 2009).

O método Delphi mostrou-se pertinente para o objetivo proposto diante do viés conceitual, sob o qual o trabalho se orienta. Trata-se de um método que busca obter o consenso de opiniões de um grupo de especialistas sobre determinadas questões. De acordo com Wright e Giovinazzo (2013), o método baseia-se no aproveitamento estruturado da

\begin{tabular}{|c|}
\hline RDBCI: Rev. Digit. Bil \\
\hline
\end{tabular}


expertise de um painel de especialistas com o pressuposto de que, quando organizado adequadamente, o julgamento coletivo pode se constituir melhor opinião do que de um único indivíduo.

A pesquisa ocorreu em duas etapas. A primeira foi um curso de formação básica em letramento informacional. Na segunda etapa, ocorreu a aplicação de questionários com feedbacks aos participantes entre cada rodada da coleta. Os instrumentos escolhidos foram, nessa abordagem, considerados complementares e dependentes, utilizados conforme a necessidade de resposta para cada objetivo específico.

Para formação do grupo de especialistas, foram escolhidos os professores que preencheram os requisitos: 1) formados em Arte, independente da linguagem artística (música, dança, artes cênicas ou artes plásticas), 2) atuação presente em regência de classe no ensino médio na rede pública de ensino do Distrito Federal, 3) voluntários com disponibilidade de tempo para participar.

Cabe ressaltar que o Delphi não consiste em levantamento estatisticamente representativo da opinião do grupo amostrado, mas sim, consulta a um grupo seleto de especialistas que preencham os requisitos exigidos para pesquisa. Assim, as questões de validade estatística da amostra e dos resultados não se aplicam (WRIGHT; GIOVINAZZO, 2000).

Para abordar potenciais participantes e divulgar a formação do grupo de especialistas em Arte Educação foram afixados cartazes na Regional de Ensino. Além disso, foram enviados convites aos professores com o perfil exigido.

De posse das confirmações dos interessados em participar, marcou-se um encontro para realização do curso de letramento informacional. O curso, de formação básica, contou com a participação de $75 \%$ dos docentes que compõem a população estipulada. Realizou-se em 18 de novembro de 2015, na regional de ensino do Recanto das Emas, e em três horas de duração foi realizada uma contextualização da temática a partir da introdução denominada informação, educação e sociedade, e posteriormente, abordados os aspectos históricos do letramento informacional, o conceito e os conteúdos extraídos da obra de Gasque Letramento Informacional: Pesquisa, Reflexão e Aprendizagem. Como estratégias de aprendizagem foram realizadas apresentação de slides, exposição do conteúdo e distribuição de materiais de estudos, que serviu como suporte teórico para posteriores respostas.

Após a realização do curso, na segunda quinzena de novembro de 2015, iniciou-se a aplicação do Delphi. O questionário da primeira rodada foi enviado em duas opções impresso ou por meio eletrônico - aos participantes da pesquisa.

De posse dos dados coletados na primeira rodada, foi realizada a sumarização dos resultados e repassada aos respondentes como primeiro feedback. Wrigth e Giovinazzo (2000) argumentam que, nesse momento, os respondentes podem reavaliar as respostas do

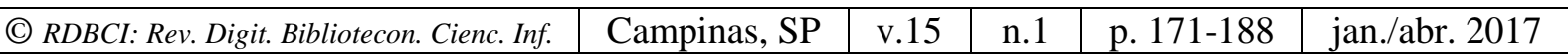


primeiro questionário, considerando a representação estatística disponibilizada. A partir das informações gerais, sintetizadas nessa etapa, elaborou-se o segundo questionário.

A segunda rodada, com intuito de melhorar a precisão dos dados, consistiu na distribuição dos questionários, conforme a habilitação profissional de cada participante que concluiu a fase anterior da pesquisa, exceto o questionário relacionado ao conteúdo de Arte/Música, descartado por não haver respondentes com expertise na área. Para Thompson (2009), a realização de poucas rodadas pode ser justificada pela clareza e objetividade alcançadas na coleta. Novamente deu-se outro feedback aos participantes da pesquisa e a oportunidade de reavaliação das respostas. No intuito de evitar incorrer no erro apontado por Wrigth (1985) - a possibilidade de forçar o consenso indevidamente na aplicação do Delphi foi encerrado neste momento, após cinco meses de duração, o processo de coleta.

Os dados coletados - on-line e em formulários impressos - foram tabulados, excluindo-se as divergências e considerando as convergências como consenso dos especialistas. Assim, geraram-se os dados finais da pesquisa, sujeitos à análise para a redação da proposta de integração dos conteúdos de letramento Informacional aos conteúdos de Arte.

\section{APRESENTAÇÃo E ANÁLISE dOS RESULTADOS}

A apresentação dos dados obtidos nas distintas fases da pesquisa, bem como análise dos resultados relacionam-se aos objetivos específicos desse estudo. Para melhor compreensão, a análise realizou-se conforme objetivo correspondente.

Objetivo: promover formação básica sobre letramento informacional aos docentes.

O planejamento, a organização e a realização do curso básico de letramento informacional propiciado aos docentes especialistas, antes da aplicação dos questionários, mostraram-se de suma importância para a aquisição dos conhecimentos sobre o assunto. Os participantes tiveram oportunidade de analisar propostas de interligação dos conteúdos de arte aos conteúdos de letramento informacional.

Porém, o curso foi de curta duração (três horas), fato que não permitiu, e não era o objetivo, o aprofundamento dos aspectos teórico-científicos da área. Assim, os docentes esclareceram assuntos incompreendidos e tiraram dúvidas sobre a pesquisa, porém ainda houve respondente que considerou os "conteúdos e habilidades do letramento informacional empíricos e rasos." Isso pode ter interferido no julgamento do respondente quanto à viabilidade de aplicação dos referidos conteúdos nas escolas públicas do Distrito Federal.

No geral, o conteúdo apresentado no curso mostrou-se suficiente para o objetivo almejado. Contudo, vale ressaltar que o ideal é que os cursos ocorram por meio de estratégias

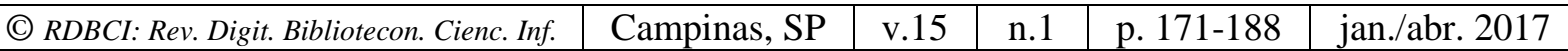


que propiciem a reflexão e a aplicação dos conteúdos durante um período de tempo, que possibilite aprendizagem mais robusta (GASQUE, 2012).

Objetivo: identificar conteúdos de letramento informacional relacionados aos conteúdos de Arte.

A primeira rodada de questionário, realizada entre novembro de 2015 e março de 2016, seguida de feedback aos participantes, forneceu os dados para o cumprimento do objetivo. A matriz de conteúdos de letramento informacional aplicada ao ensino médio, proposta por Gasque (2012), foi avaliada, item a item, pelos professores por meio de questões fechadas que indicavam ou não, a possibilidade de relação entre os conteúdos das duas áreas.

A referida matriz propõe para o primeiro ano do ensino médio os seguintes conteúdos (GASQUE, 2012):

Quadro 1. Propostas de conteúdos de letramento informacional para o ensino médio (primeiro ano)

PROPOSTAS DE CONTEÚDOS DE LETRAMENTO INFORMACIONAL ENSINO MÉDIO

\section{Primeiro Ano}

\begin{tabular}{|c|c|}
\hline Conteúdos & Habilidades \\
\hline Pesquisa & $\begin{array}{l}\text { - Utiliza operadores booleanos - e,ou,não - e técnica de truncamento para } \\
\text { pesquisar em banco de dados (em especial de bibliotecas). } \\
\text { - Descreve e emprega os elementos principais do texto científico - introdução, } \\
\text { desenvolvimento e conclusão. } \\
\text { - Descreve as características da informação científica. } \\
\text { - Conhece as boas regras para construção de texto científico. } \\
\text { - Utiliza as normas - Referência Bibliográfica, Apresentação de relatórios técnico- } \\
\text { científicos e Sumário- procedimentos da ABNT para apresentação da pesquisa. }\end{array}$ \\
\hline $\begin{array}{l}\text { Resumo técnico - } \\
\text { Científico }\end{array}$ & $\begin{array}{l}\text { - Compreende a importância dos resumos como disseminadores de informação. } \\
\text { - Descreve e emprega as normas gerais do resumo. } \\
\text { - Descreve as características dos principais tipos de resumo técnico-científico. } \\
\text { - Elabora resumo indicativo e informativo. }\end{array}$ \\
\hline Referência & $\begin{array}{l}\text { - Define o que é referência. } \\
\text { - Identifica os elementos principais da referência. } \\
\text { - Explica as normas gerais da referência. } \\
\text { - Descreve as formas de entrada de autoria e os tipos de autoria. } \\
\text { - Referencia monografia no todo ou em partes. } \\
\text { - Referencia publicações seriadas no todo e artigos de períodos. } \\
\text { - Referencia sites da internet. }\end{array}$ \\
\hline $\begin{array}{l}\text { Citação } \\
\text { bibliográfica }\end{array}$ & $\begin{array}{l}\text { - Explica o que é plágio. } \\
\text { - Descreve os pontos principais da legislação sobre o plágio/autoria. } \\
\text { - Compreende a importância do uso da norma de Informação e documentação- } \\
\text { Citações documentos- Apresentação NBR } 10520 \text {. } \\
\text { - Descreve os termos usados na norma: citação, citação de citação, citação direta, } \\
\text { citação indireta, notas de referência, notas de rodapé, notas explicativas. } \\
\text { - Explica as normas gerais de citação. }\end{array}$ \\
\hline
\end{tabular}

\begin{tabular}{|l|l|l|l}
\hline v.15 & n.1 & p. 171-188 & jan./abr. 2017 \\
\hline
\end{tabular}




\begin{tabular}{|l|l|}
\hline Mapa conceitual & $\begin{array}{l}\text { - Conhece os sistemas de chamada (numérico e autor-data). } \\
\text { - Explica o que é mapa conceitual e a importância para os estudos. } \\
\text { - Descreve as características do mapa conceitual. } \\
\text { - Identifica e lista os conceitos/palavras-chave do conteúdo de pesquisa. } \\
\text { - Elabora mapa conceitual manual e com utilização de softerware. }\end{array}$ \\
\hline Biblioteca & $\begin{array}{l}\text { - Conhece as normas da biblioteca. } \\
\text { - Compreende o sistema de organização da biblioteca (classificação, número de } \\
\text { chamada, sistema de indexação). } \\
\text { - Sabe buscar informações no catálogo da biblioteca. } \\
\text { Descreve os serviços e produtos da biblioteca. }\end{array}$ \\
\hline Introdução às \\
técnicas de estudo & $\begin{array}{l}\text { - Planejamento do plano de estudo. } \\
\text { - Tarefas do processo de estudo: antecipar a informação geral do texto; leitura do } \\
\text { texto; análise dos conteúdos do tema; síntese da informação; } \\
\text { esquemas/diagramas; condiçães básicas para melhorar a fixação e a } \\
\text { recuperação das informaç̧̃̃es. }\end{array}$ \\
\hline
\end{tabular}

Fonte: Gasque, 2012.

Para o segundo ano, os conteúdos propostos são:

Quadro 2. Propostas de conteúdos de letramento informacional para o ensino médio (segundo ano)

\section{PROPOSTAS DE CONTEÚDOS DE LETRAMENTO INFORMACIONAL ENSINO MÉDIO}

\section{Segundo Ano}

\begin{tabular}{|l|l|}
\hline Conteúdos & Habilidades \\
\hline Pesquisa & $\begin{array}{l}\text { - Descreve as fases de uma pesquisa. } \\
\text { - Compreende o que é projeto de pesquisa. } \\
\text { - Define e articula as necessidades de informação. } \\
\text { - Identifica os tipos e fontes potenciais de informação. } \\
\text { - Constrói e implementa projetos de estratégias de busca e informação. } \\
\text { - Diferencia os diferentes tipos de informação: científica, tecnológica e atualizada. } \\
\text { - Descreve e identifica critérios gerais para avaliar a qualidade da informação. } \\
\text { - Compara dois ou mais conceitos sobre o mesmo assunto, de diferentes autores, } \\
\text { e identifica os pontos convergentes, divergentes e a relevância para a pesquisa. } \\
\text { - Compreende o que é pesquisa qualitativa e quantitativa. }\end{array}$ \\
\hline Apresentação de & $\begin{array}{l}\text { - Descreve os elementos principais do trabalho acadêmico, pré-textuais, textuais } \\
\text { e pós-textuais. NBR 15724 } \\
\text { trabalho } \\
\text { acadêmico }\end{array}$ \\
\hline Referência & $\begin{array}{l}\text { - Define o que é referência. } \\
\text { - Descreve a terminologia utilizada na norma de referência- NBR } 6023 . \\
\text { - Referencia artigo de periódico. } \\
\text { - Referencia artigo de jornal impresso em meio eletrônico. } \\
\text { - Referencia evento como todo impresso e em meio eletrônico. }\end{array}$ \\
\hline
\end{tabular}

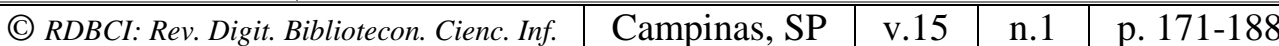
jan./abr. 2017 


\begin{tabular}{|l|l|}
\hline Artigo & - Compreende a referência como importante fonte de informação. \\
& $\begin{array}{l}\text { - } \text { Compreende a diferença entre projeto e artigo. } \\
\text { - Descreve os elementos principais do artigo. } \\
\text { - Elabora pequenos artigos. }\end{array}$ \\
\hline $\begin{array}{l}\text { Resumo técnico- } \\
\text { científico }\end{array}$ & $\begin{array}{l}\text { - Descreve e emprega as normas gerais do resumo. } \\
\text { - Descreve as características do resumo crítico. } \\
\text { - Elabora resumo crítico. }\end{array}$ \\
\hline $\begin{array}{l}\text { Técnica de coleta } \\
\text { de dados }\end{array}$ & $\begin{array}{l}\text { - Descreve as principais técnicas de coleta de dados. } \\
\text { - Descreve as vantagens e desvantagens do questionário. } \\
\text { - Elabora questionário. } \\
\text { - Aplica o questionário. } \\
\text { - Tabula os dados do questionário. } \\
\text { - Analisa os dados do questionário. }\end{array}$ \\
\hline
\end{tabular}

Fonte: Gasque, 2012

No terceiro ano, a proposta é ensinar os conteúdos relacionados:

Quadro 3. Propostas de conteúdos de letramento informacional para o ensino médio (terceiro ano)

\begin{tabular}{|c|c|}
\hline & $\begin{array}{c}\text { PROPOSTAS DE CONTEÚDOS DE LETRAMENTO INFORMACIONAL } \\
\text { ENSINO MÉDIO }\end{array}$ \\
\hline \multicolumn{2}{|l|}{ Terceiro Ano } \\
\hline Conteúdos & Habilidades \\
\hline Ciência & $\begin{array}{l}\text { - Conceitua o que é ciência. } \\
\text { - Compreende o que é paradigma } \\
\text { - Descreve a evolução do paradigma científico. } \\
\text { - Compreende a necessidade do pensamento complexo. } \\
\text { - Descreve os limites da ciência. } \\
\text { - Identifica as principais questões éticas vinculadas à ciência. } \\
\text { - Descreve os principais produtos científicos e fontes científicas. } \\
\text { - Compreende a importância da comunicação científica. }\end{array}$ \\
\hline Pesquisa & $\begin{array}{l}\text { - Explica o conceito de letramento informacional e sua importância. } \\
\text { - Descreve, em linhas gerais, os principais padrões de letramento informacional. } \\
\text { - Identifica assunto de interesse para pesquisar. } \\
\text { - Elabora pré-projeto de pesquisa. } \\
\text { - Executa a pesquisa. } \\
\text { - Elabora monografia da pesquisa. } \\
\text { - Apresenta trabalho de pesquisa. }\end{array}$ \\
\hline $\begin{array}{l}\text { Técnica de coleta } \\
\text { de dados }\end{array}$ & $\begin{array}{l}\text { - Descreve as principais técnicas de coletas de dados. } \\
\text { - Descreve as vantagens e desvantagens da observação. } \\
\text { - Constrói grelha de observação. } \\
\text { - Aplica o instrumento de coleta de dados. } \\
\text { - Tabula os dados da observação. } \\
\text { - Analisa os dados da observação. } \\
\text { - Descreve as vantagens e desvantagens da entrevista. } \\
\text { - Elabora entrevista. } \\
\text { - Aplica a entrevista. } \\
\text { - Tabula os dados da entrevista. } \\
\text { - Analisa os dados da entrevista. }\end{array}$ \\
\hline
\end{tabular}


Fonte: GASQUE, 2012.

Os resultados mostram que 77,5\% dos conteúdos do primeiro ano foram julgados pelos participantes possíveis de ser relacionados com os conteúdos de Arte. O percentual chegou a $90 \%$ dos conteúdos do segundo ano e $88,5 \%$ dos conteúdos do terceiro ano. Tais percentuais podem ser compreendidos ao considerar a argumentação de Fialho (2013), em que o desenvolvimento do letramento informacional deve observar as especificidades de cada disciplina.

É possível constatar com os dados coletados nessa fase, que a parceria entre corpo docente e bibliotecários é indispensável. Jumonville (2014) afirma que a referida relação é fundamental para o sucesso dos programas de letramento Informacional, em especial ao considerar a realização do trabalho colaborativo entre eles (KOVALIK, YUTZEY, PIAZZA 2012). Sobre isso, $50 \%$ dos especialistas consultados consideraram que os conteúdos do primeiro ano do ensino médio de possível aplicação na disciplina Arte, exigem o auxílio do bibliotecário. Os percentuais relacionados à participação do bibliotecário diminuíram a medida que os estudantes se tornam mais autônomos, ou seja, caem para 38,5\% no segundo ano e para $13 \%$ no terceiro ano.

Nessa fase da pesquisa, foram apontados alguns desafios quanto à aplicação do letramento informacional em relação ao currículo. Observou-se que o currículo não contempla as atuais necessidades de informação, mas a carga horária semanal de aulas de arte é insuficiente para o cumprimento do currículo da disciplina agregado ao de letramento informacional. Mais ainda, foram citados os problemas das unidades de ensino relacionados à estrutura física, com destaque para a falta de bibliotecas e de laboratórios de informática. Além disso, os professores relataram obstáculos em relação à presença dos bibliotecários, quase inexistentes no quadro de funcionários da rede pública de ensino e também a ausência de formação em letramento informacional para os professores e os estudantes.

Apesar de a legislação sobre bibliotecas públicas prever a universalização das bibliotecas nas instituições de ensino do país (BRASIL, 2010) e de haver estudos que mostram a relação entre desempenho de aprendizagem dos estudantes e frequência na bibliotecas, há vários estudos que mostram os problemas das bibliotecas escolares no Brasil. Esses problemas abrangem, por exemplo, quantidade insuficiente de unidades, acervo pequeno e desatualizado, espaços físicos precários, bem como déficit em recursos financeiros e tecnológicos (CAMPELLO,2010; BERNARDINO; SUAIDEN, 2011; GASQUE, 2010; SOARES, 2004).

Apesar dos desafios, constata-se que os pesquisados consideraram viável a implementação de programas de letramento informacional nas escolas públicas do Distrito Federal. Um dos fatores que pode influenciar nesse processo é justamente a relação convergente entre os conteúdos de letramento informacional e os de Arte.

Sobre a relação colaborativa almejada entre as partes envolvidas no processo de

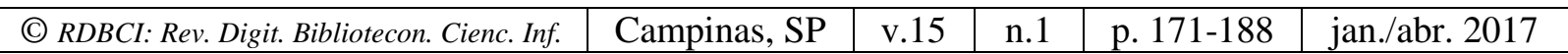


ensino do letramento informacional - bibliotecários e docentes das disciplinas curriculares Lima (2012) reforça o posicionamento de Macklin e Fosmire (2004) sobre a diferença entre as estruturas epistemológicas e os processos investigativos das diferentes áreas de conhecimento não interferir na globalização dos conteúdos do letramento informacional. Para garantir a eficácia do ensino, é importante manter a colaboração e a integração entre currículos.

Objetivo: identificar estratégias e sugestões dos participantes da oficina para trabalhar o LI em sala de aula.

Um passo relevante para a aplicação da proposta construída é a identificação de estratégias práticas para trabalhar o letramento em sala de aula. A maioria das repostas obtidas sugere que os conteúdos de letramento informacional, por serem, em sua maioria, ações práticas de busca e uso da informação, sejam aplicados aos conteúdos teóricos de Arte, a fim de promover a aprendizagem de ambos os conteúdos e alcançar os objetivos curriculares de Arte.

A ausência de sugestões mais específicas sobre atividades diferentes do modelo tradicional de educação permite entender que, a barreira apontada por Gasque e Tescarolo (2010) relacionada à dificuldade em mudar a cultura pedagógica, ainda vigora entre os docentes de artes do ensino médio da rede pública de ensino do Distrito Federal. Muitos deles ainda ministram aulas centradas na transmissão de conteúdos pelo professor, em detrimento de atividades que estimulem a construção do conhecimento pelo estudante, por meio da valorização das experiências, a fim de estabelecer um processo de aprendizagem significativa, conforme preconiza Ausubel (2003).

Porém, as sugestões coletadas corroboram com o pressuposto difundido por Gasque (2012), que recomenda que o letramento informacional não seja implementado como treinamento ou atividade pontual, mas integrado ao currículo. Esse argumento é condizente com Mata (2014), que defende a abordagem do letramento informacional direcionada ao currículo e ao plano das disciplinas.

Objetivo: elaborar proposta de integração dos conteúdos de letramento informacional aos conteúdos de Arte do Ensino Médio.

O resultado da primeira rodada de questionário e feedback consiste em uma proposta de conteúdos de letramento informacional integrados aos conteúdos de Arte do ensino médio. Os conteúdos de Arte relacionados ao desenvolvimento prático de cada linguagem não foram associados aos conteúdos de letramento devido à especificidade e à natureza das atividades, entretanto os resultados indicam que todo e qualquer conteúdo teórico de Arte é passível de integração.

Os conteúdos de busca e uso da informação apresentados por Gasque (2012) mostram-se importantes, de acordo com os preceitos da Information Power (AASL,1988), \begin{tabular}{l} 
(C) RDBCI: Rev. Digit. Bibliotecon. Cienc. Inf. \\
\hline
\end{tabular} 
para que os estudantes aprendam a lidar com a informação, bem como com a responsabilidade social imbuída nessa prática. Além disso, permitem desenvolver mecanismos de aprendizagem autônoma e promover educação emancipatória (CAMPELLO, 2003; PERES, 2011).

Da matriz curricular, sugerida por Gasque (2012), para o primeiro ano do ensino médio, os seguintes conteúdos, sobre pesquisa e resumo técnico científico, foram indicados pelos pesquisados para integração:

- Pesquisa com operadores booleanos - e, ou, não - e técnica de truncamento para pesquisar em banco de dados (em especial de bibliotecas).

- Descreve e emprega os elementos principais do texto científico - introdução, desenvolvimento e conclusão.

- Utiliza as normas - Referência Bibliográfica, Apresentação de relatórios técnico-científicos e Sumário - procedimentos da ABNT para apresentação da pesquisa.

- Elabora resumo indicativo e informativo.

Os conteúdos relacionados à referência, citação bibliográfica e introdução às técnicas de estudo, ainda do primeiro ano, foram:

- Referencia monografia no todo ou em partes.

- Referencia publicações seriadas no todo e artigos de períodos.

- Referencia sites da internet.

- Realiza planos de estudo

Para constituir a proposta de interligação de conteúdos referentes ao segundo ano do ensino médio, os conteúdos de pesquisa, apresentação de trabalhos acadêmicos e referência, indicados foram:

- Constrói e implementa projetos de estratégias de busca de informação.

- Compara dois ou mais conceitos sobre o mesmo assunto, de diferentes autores, e identifica os pontos convergentes, divergentes e a relevância para a pesquisa.

- Emprega a norma para estruturação do trabalho acadêmico

- Referencia artigo de periódico.

- Referencia artigo de jornal impresso em meio eletrônico.

- Referencia evento como todo impresso e em meio eletrônico.

Os conteúdos relacionados ao artigo, resumo técnico-científico e técnica de coleta de dados são:

\begin{tabular}{l|l|l|l|l|l} 
(C) RDBCI: Rev. Digit. Bibliotecon. Cienc. Inf. & Campinas, SP & v.15 & n.1 & p. 171-188 & jan./abr. 2017 \\
\hline
\end{tabular} 
- Elabora pequenos artigos.

- Elabora resumo crítico.

- Elabora questionário.

- Aplica o questionário.

- Tabula os dados do questionário.

- Analisa os dados do questionário.

Para o terceiro ano os conteúdos indicados são referentes à pesquisa e de técnicas de coleta de dados.

- Elabora pré-projeto de pesquisa.

- Executa a pesquisa.

- Apresenta trabalho de pesquisa.

- Constrói grelha de observação.

- Aplica o instrumento de coleta de dados.

- Tabula os dados da observação.

- Analisa os dados da observação.

- Elabora entrevista.

- Aplica a entrevista.

- Tabula os dados da entrevista.

- Analisa os dados da entrevista.

Os demais conteúdos analisados como de possível aplicação nas aulas de Arte, que não foram relacionados a conteúdo algum da disciplina, são conteúdos conceituais que precedem os conteúdos procedimentais descritos. A não associação reflete o pouco domínio teórico dos pesquisados sobre o letramento informacional. Tal realidade sugere a necessidade de debater se esta visão restrita dos profissionais docentes, corresponde aos objetivos almejados pelos especialistas que propõem a implementação do letramento informacional nas escolas. Mais ainda requer, assim como Gasque e Tascarolo (2010) descrevem, investimentos consideráveis na formação dos professores e na mudança de cultura pedagógica vigente.

\section{CONCLUSÕES E RECOMENDAÇões}

Os resultados da pesquisa mostram a possibilidade de uma prática pedagógica em Arte voltada para a formação discente em letramento informacional. Grande parte dos docentes pesquisados considerou viável a integração da disciplina aos conteúdos de letramento informacional, da matriz original proposta Gasque (2012).

Apesar do cenário favorável, cabe destacar que os participantes do curso de formação básica não tiveram até a pesquisa contato com os princípios teóricos, estudos e práticas de letramento informacional. Tal fato sugere a necessidade de maior estreitamento de laços e

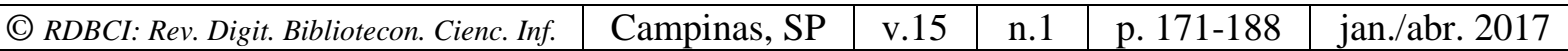


comunicação entre a ciência da informação e a educação. Dudziak (2003) verificou quadro semelhante ao constatar, junto à comunidade acadêmica, a falta de uma política integradora entre programas de letramento informacional e os processos de ensino-aprendizagem.

Os desafios para a efetiva prática da proposta coincidem com as barreiras apontadas por Gasque e Tescarolo (2010). Dentre elas, destaca-se a incipiência da formação em letramento informacional dos professores, fator que precisa ser superado por meio de estímulo à oferta de cursos de formação continuada na área.

Quanto aos desafios decorrentes da organização curricular, Gasque (2012) ressalta que os programas de letramento informacional devem ser planejados pelas instituições de ensino, de acordo com as necessidades e a realidade em que estão inseridas. As escolas, por meio do projeto político pedagógico, têm a oportunidade e o respaldo legal necessários para superar as limitações apresentadas.

Os problemas de infraestrutura inadequada de informação, como denomina Gasque (2012), nesse estudo descritos, como a ausência de bibliotecas, de acervo relevante e de laboratórios de informática, são realidades na rede pública de ensino, que carece ainda de bibliotecários. Fialho (2013) ao reconhecer a realidade insatisfatória de muitas escolas brasileiras, sugere que as práticas de letramento informacional sejam adaptadas aos recursos pessoais e materiais disponíveis.

As sugestões de estratégias coletadas exigem atenção, reflexão e parecer por parte dos especialistas em letramento informacional, por consistirem, resumidamente, em trabalhar os conteúdos de letramento informacional em função da aprendizagem dos conteúdos de Arte. Esse entendimento pode ser compreendido como uma maneira simplificada de colocar em prática o letramento informacional na sala de aula, ou reducionismo impróprio para dimensão dos ideais da área.

Por fim, este estudo ressalta que a educação voltada para o letramento informacional é uma tarefa complexa, como argumenta Dudziak (2005). Apesar dos desafios identificados, espera-se que a proposta de interligação dos conteúdos de letramento informacional aos conteúdos de Arte, resultante dessa pesquisa, contribua para a organização de práticas de letramento informacional nas escolas, tendo como agentes arte educadores. 


\section{LA CONSTRUCCIÓN DE UN PROGRAMA DE ALFABETIZACIÓN INFORMACIONAL Y LA EDUCACIÓN ARTÍSTICA}

RESUMEN: Analiza la interconexión de los contenidos de habilidades informativas de arte contenido en la escuela secundaria por encuesta descriptiva de la Secretaría de educadores de arte de educación del Distrito Federal, la enseñanza de Recanto das Emas regionales. Los profesores encuestados participaron en curso de formación básica en habilidades informativas con el fin de apoyar la última etapa que consistía en responder a cuestionarios rondas intercalados con retroalimentación. El estudio utilizó el método Delphi, los instrumentos de investigación se estructuraron cuestionarios con preguntas cerradas y abiertas. Los resultados demostraron la factibilidad de aplicación de la propuesta, a pesar de los retos que hay que superar, principalmente relacionados con el incipiente en la formación en alfabetización informacional de los profesores, en general, la infraestructura deficiente de las escuelas y la organización curricular actual.

PALABRAS CLAVE: Alfabetización informacional. Multiletramento. Educación Artística.

Submetido em: 08/06/2016

Aceito em: 11/07/2016

Publicado em: 17/11/2016

\section{REFERÊNCIAS}

AMERICAN ASSOCIATION OF SCHOOL LIBRARIANS; ASSOCIATION FOR EDUCATIONAL COMMUNICATIONS. Information power: Building partnerships for learning. American Library Association, 1998.

AUSUBEL, D. P. Aquisição e retenção de conhecimentos: uma perspectiva cognitiva. Lisboa: Plátano, 2003.

BARBOSA, Ana Mae. Utópicos, Tópicos. Belo Horizonte: C/Arte, 1998.

BERNARDINO, Maria Cleide Rodrigues; SUAIDEN, Emir José. O papel social da biblioteca pública na interação entre informação e conhecimento no contexto da ciência da informação. Perspectivas em ciência da informação, v. 16, n. 4, p. 29-41, 2011. Disponível em : <http://www.scielo.br/pdf/pci/v16n4/v16n4a04>. Acesso em: 11 mai. 2016.

BEVILAQUA, Raquel. Novos estudos do letramento e multiletramentos: divergências e confluências. REVLET-Revista Virtual de Letras, v. 5, n. 01, 2013.

BHATTACHERJEE, Anol. Social Science Research: Principles, and Practices. Flórida: Textbooks Collection, 2012. Disponível em: <http://scholarcommons.usf.edu /oa_textbooks/3> Acesso em: 16 jun. 2014. 
BRASIL. Lei $\mathbf{n}^{0}$ 12.244/ 2010: Universalização das bibliotecas nas instituições de ensino do País de 24 de maio de 2010. Disponível em: < http://www.planalto.gov.br/ccivil_03/_ato2007-2010/2010/lei/112244.htm >. Acesso em : 7 mar. 2016.

BRASIL. Lei no 13.278/2016: Diretrizes e bases da educação nacional, referente ao ensino da arte de 2 de maio de 2016. Disponível em: < http://www.planalto.gov.br/ccivil_03/_Ato20152018/2016/Lei/L13278.htm >. Acesso em : 7 mar. 2016.

CAMPELLO, Bernadete. O movimento da competência informacional: uma perspectiva para o letramento informacional. Ciência da Informação, Brasília, v.2, n.3, p.28-37, set./dez. 2003. Disponível em: <http://www.scielo.br/pdf/ci/v32n3/1902 1.pdf>. Acesso em: 26 de dez. 2015.

CAMPELLO, Bernadete Santos. Perspectivas de letramento informacional no Brasil: práticas educativas de bibliotecários em escolas de ensino básico. Encontros Bibli: revista eletrônica de biblioteconomia e ciência da informação, v. 15, n. 29, p. 184-208, 2010.

DEMO, Pedro. Política Social, educação e cidadania. Papirus, 1994.

DISTRITO FEDERAL. Secretaria de Educação. Currículo em movimento da Educação Básica: Ensino Médio. 2013.

DUDZIAK, Elisabeth Adriana. Competência em Informação: Melhores práticas educacionais voltadas para a information literacy. In: Congresso Brasileiro de Biblioteconomia, Documentação e Ciência da Informação, 21., 2005.Curitiba, Anais... Curitiba: Federação Brasileira de Associação de Bibliotecários, 2005. Disponível em: <http://eprints.rclis.org/6876/1/166_DUDZIAK_CBBD_2005b.pdf > . Acesso em : 23 jun. 2014.

DUDZIAK, Elisabeth Adriana. Information literacy: princípios, filosofia e prática. Ciência da Informação, Brasília, v. 32, n. 1, jan./abr. 2003

FERREIRA, Francisco. Os determinantes da desigualdade de renda no Brasil: luta de classes ou heterogeneidade educacional?. Pontifícia Universidade Católica de Rio de Janeiro, Departamento de Economia, 2000.

FIALHO, Janaina. Experiência com estudantes do ensino médio através da pesquisa escolar orientada. Perspectiva em Ciência da Informação, Belo Horizonte, v.18, n.1, p.15-25, Jan./Mar. 2013.

FLICK, Uwe. Introdução à pesquisa qualitativa. 3.ed. Porto Alegre, RS: Artmed, 2009. $405 p$.

GASQUE, Kelley Cristine G. D. Letramento informacional: pesquisa, reflexão e aprendizagem. Brasília: FCI/UNB, 2012. 178p. Disponível em: 
<http://repositorio.unb.br/bitstream/10482/13025/1/LIVRO_Letramento_Informacional.pdf>. Acesso em: 25 mar. 2014.

GASQUE, Kelley Cristine Gonçalves Dias; TESCAROLO, Ricardo. Desafios para implementar o letramento informacional na educação básica. Educação em Revista, Belo Horizonte, v. 26, n. 1, p. 41-56, abr. 2010. Disponível em: <http://www.scielo.br/pdf/edur/v26n1/03.pdf>. Acesso em: 22 maio 2015.

HARRIS, Benjamin. Communities as necessity in information literacy development: challenging the standards. The Journal of Academic Librarianship, v.34, n. 3, p.248-255, mai 2008. Disponível em: <http://www.sciencedirect.com/science/

article/pii/S0099133308000402>. Acesso em: 22 mai. 2014

JUMONVILLE, Anne. The role of faculty autonomy in a course-integrated information literacy program. Reference Services Review, v. 42, n. 4, p. 536-551, 2014.

KAUARK, Fabiana; MANHÃES, Fernanda Castro; MEDEIROS, Carlos Henrique. Metodologia da pesquisa: guia prático. Itabuna: Via Litterarum, 2010. 88p.

KOVALIK, Cindy L.; YUTZEY, Susan D.; PLAZA, Laura M. Assessing change in high school student information literacy: using the tool for real-time assessment of information literazy skills. Contemporary Issues in Education Research, v.5, n.3, 2012. Disponível em:<http://search.proquest.com/docview/141850482/fulltextPDF/EAEF22F66AAF44CPQ/1 ?accountid=26646. Acesso em: 05 Set. 2015.

LIMA, Alberto José Ferreira de. Letramento digital e letramento informacional na literatura nacional e internacional em língua inglesa. 2012. 204 f. Dissertação (mestrado em Educação) - Universidade Federal da Paraíba, João Pessoa, 2012.

LÉVY, Pierre. Cibercultura. São Paulo: Ed.34, 2000.

MACKLIN, Alexius Smith; FOSMIRE, Michael. A blueprint for progress: Collaborating with faculty to integrate information literacy into the curriculum at Purdue University. Resource sharing \& information networks, v. 17, n. 1-2, p. 43-56, 2005. Disponível em: <http://www.tandfonline.com/doi/abs/10.1300/J121v17n01_05\#.V1V4Cc6cF0s> . Acesso em: 06 jun. 2016.

MATA, Marta Leandro da. A inserção da Competência Informacional nos currículos dos cursos de Biblioteconomia no Brasil e nos cursos de Informação e Documentação da Espanha. 197fl. Tese. (Doutorado em Ciência da Informação) - Faculdade de Filosofia e Ciências, Universidade Estadual Paulista, Marília, SP, 2014. Disponível em: <http://www.marilia.unesp.br/Home/PosGraduacao/CienciadaInformacao/Dissertacoes/mata_ ml_do_mar.pdf>. Acesso em: 29 mar. 2015.

PERES, Mônica Regina. Competência informacional: educação e sociedade. Revista IberoAmericana de Ciência da Informação, v. 4, n. 1, 2012. Disponível em: < http://www.periodicos.unb.br/index.php/RICI/article/view/6159/5079 >. Acesso em: 19 de fev. 2015.

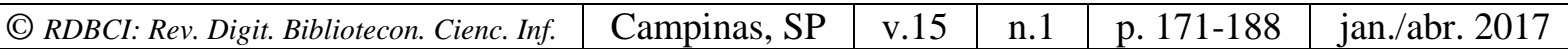


RODRIGUES, Rubson Marques. A escola e a desigualdade. Educativa, v.12, n.2, p. 371375, 2009. Disponível em: <http://mosaico.ucg.br/index.php/educativa/ article/viewFile/918/654> Acesso em: 13 jun. 2014.

ROJO, Roxane. Letramentos múltiplos, escola e inclusão social. São Paulo: Parábola Editorial, 2009, 128 p.

ROJO, Roxane; MOURA, Eduardo. Multiletramentos na escola. São Paulo: Parábola, 2012.

SEKARAN, Uma. Research methods for business: a skill-building approach. 4.ed. Nova Iorque: John Wiley \& Sons, 2003.

SOARES, J. F. O efeito da escola no desempenho cognitivo de seus alunos. Revista Electrónica Iberoamericana sobre Calid, Eficácia y Cambio en Educación, Madrid, v. 2, n. 2, p. 83-104, 2004. Disponível em: 〈https://repositorio.uam.es/handle/10486/660750>. Acesso em: 10 mar. 2016.

THOMPSON, Miles. Considering the implication of variation within Delphi Research. Family Practice, Oxford, UK, v.26, p. 420-424, 2009. Disponível em: <http://fampra.oxfordjournals.org/content/26/5/420.full >. Acesso em: 7 maio 2015.

WRIGHT, J. T. C.; GIOVINAZZO, R. A. Delphi: uma Ferramenta de apoio ao planejamento prospectivo. Cadernos de Pesquisa em Administração, São Paulo, v.1,n.12, p.54-65, 2000. Disponível em: <http://www. iea. usp. br/iea/tematicas/futuro/projeto/delphi. pdf.>. Acesso em: 14 jun. 2015.

WRIGHT, James TC. A técnica Delphi: Uma ferramenta útil para o planejamento do Brasil. III Encontro Brasileiro de Planejamento Empresarial - "Como Planejar 86", v. 86, p. 199-207, 1985.

ZABALA, Antoni. A prática educativa: como ensinar. Penso, 2015.

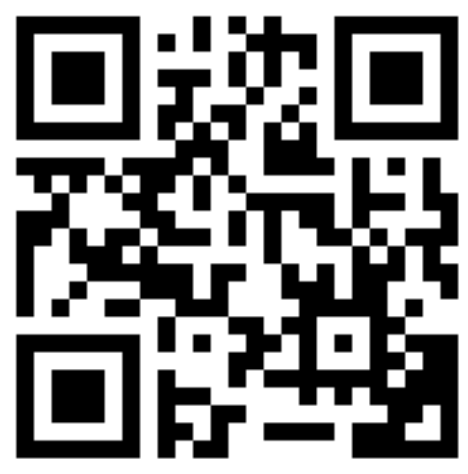

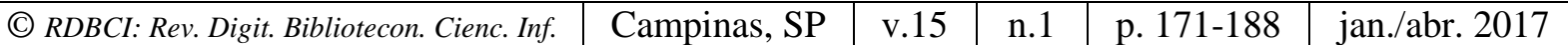

